\title{
Insight into ground deformations at Lascar volcano (Chile) from SAR interferometry, photogrammetry and GPS data: Implications on volcano dynamics and future space monitoring
}

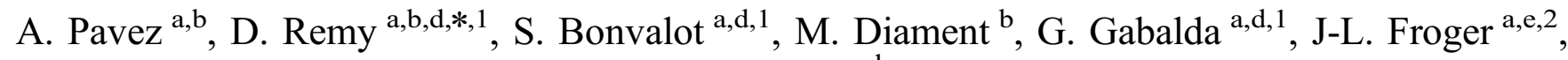 \\ P. Julien ${ }^{\mathrm{c}}$, D. Legrand ${ }^{\mathrm{d}}$, D. Moisset ${ }^{\mathrm{c}}$ \\ a Institut de Recherche pour le Développement (IRD)—Casilla 53390, Correo Central, Santiago, Chile \\ ${ }^{\mathrm{b}}$ Institut de Physique du Globe de Paris-4 Place Jussieu, Case 89, 75252 Paris Cedex 05, France \\ c Institut Géographique National, Laboratoire en Méthodes d'Analyse et de Traitement d'Images pour la Stéréorestitution (MATIS)—2, \\ avenue Pasteur, 94165 Saint-Mandé Cedex, France

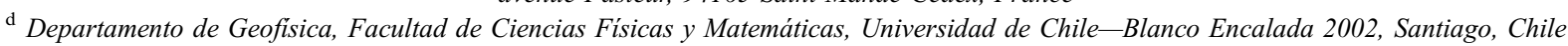 \\ e Departamento de Geología, Facultad de Ciencias Físicas y Matemáticas, Universidad de Chile-Plaza Ercilla 803, Santiago, Chile
}

\begin{abstract}
We present a detailed study of Lascar volcano (Chile) based on the combination of satellite, aerial and ground-based data, in order (i) to better characterize the deformation style of Andean explosive volcanoes, and (ii) to provide new insights on the potential of space techniques to monitor active volcanic deformations on such edifices. Lascar is one of the most active volcanoes in Central Andes characterized by a recent cyclic activity. Additionally, it is located in favourable conditions for radar imaging. Lascar thus offers very good conditions for studying large to small scale ground deformations associated with volcano dynamics. The analysis of InSAR (Synthetic Aperture Radar interferometry) time series data from the European and Japanese satellites (ERS, JERS) acquired between 1993 and 2000, encompassing three eruptive events, confirmed the absence of broad far-field deformation signal. Thus during the recent activity of Lascar we discard significant magmatic input at depth. The following approaches were used to improve the InSAR signal/noise ratio in order to detect possible local deformation. We carried out a quantitative evaluation of the potential tropospheric contribution in INSAR interferograms for the Salar de Atacama-Lascar area using radar (ASARENVISAT) and spectrometer (MODIS) data. We also used an accurate aerial photogrammetric and GPS constrained DEM in our InSAR data reprocessing. We find a co-eruptive ground-deformation confined into the summit crater for the 1995 eruption. This deformation has spatial dimension of 500 by $400 \mathrm{~m}$ and relates to a subsidence of crater floor up to $17 \mathrm{~mm}$. We interpret it as pressure or volume decrease at subsurface levels below the active crater. Our study made it possible to image a new near-field volcanic deformation confined within the summit crater of the Lascar volcano. It also demonstrates that the combination of precise photogrammetry DEM and INSAR data can significantly improve our ability to remotely sense subtle surface deformation on these explosive volcanoes. This methodology might contribute to better understand volcano dynamics and to complement their monitoring in remote areas.
\end{abstract}

Keywords: Volcanic deformation; Satellite monitoring; Atmospheric effects; Andes

\footnotetext{
* Corresponding author. Institut de Recherche pour le Développement (IRD) - Casilla 53390, Correo Central, Santiago, Chile.

E-mail address: remy@dgf.uchile.cl (D. Remy).

${ }^{1}$ Also at: UMR5563/LMTG, Obs. Midi-Pyrénées-14, av. E. Belin, 31400 Toulouse, France.

${ }^{2}$ Also at: UMR6524/LMV—5 rue Kessler, 63038 Clermont-Ferrand cedex, France.
}

\section{Introduction}

Numerous studies have demonstrated the potential of satellite SAR (Synthetic Aperture Radar) interferometry for measuring ground deformation related to volcanic activity (Dzurisin, 2003; Massonnet \& Feigl, 1998; Zebker et al., 2000). They provided a valuable help to characterize deformation styles on a large variety of volcanic edifices in 
conjunction with existing monitoring networks or also as a unique tool for measuring ground deformations in remote areas. Nevertheless, explosive andesitic volcanoes, such as most of Andean strato-volcanoes, are the most difficult to survey with these techniques (Zebker et al., 2000). This is due to their specific geometry (steep slopes) or to severe environmental conditions (e.g., high elevation, possible vegetation or snow cover for instance). As a consequence, the ground deformation style on andesitic volcanoes is still not well understood (Sparks, 2003) and very few results have been presented for these edifices, even though significant topographic changes produced by magmatic fluid migrations are likely to occur over various scales, including large scale deformation, lava dome growth and collapse, flank destabilization, etc. (e.g. Beauducel \& Cornet, 1999; Shepherd et al., 1998).

In their recent large scale satellite SAR interferometry (InSAR) survey of Central Andes using ERS data, Pritchard and Simons (Pritchard \& Simons, 2002, 2004) provided the first evidence of broad (tens of kilometer wide) roughly axisymetric deformation signals over Andean volcanic centres, similar to those also observed on other andesitic active volcanoes (Dvorak \& Dzurisin, 1997; Dzurisin, 2003; Pritchard \& Simons, 2004). These deformation signals on Andean volcanoes were interpreted as magmatic volume changes at intermediate depths between 5 to $17 \mathrm{~km}$. Most of these deformation signals were detected on centres which are not currently classified as potentially active volcanoes. However, the study of Pritchard and Simons $(2002,2004)$ did not reveal any detectable ground deformation over edifices that experienced eruptive activities during the period covered by the satellite observations.

Of the active edifices of the Central Andes, Lascar volcano (5592 $\mathrm{m} ; 23^{\circ} 22^{\prime} \mathrm{S}, 67^{\circ} 44^{\prime} \mathrm{W}$ ), located on the eastern side of the Salar de Atacama Basin in northern Chile (Fig. 1) has undergone the most active eruptive sequence during these last few years. Its recent activity is characterized by repetitive dome growth and subsidence (4 documented cycles between 1984 to 1993) accompanied by vigorous degassing and explosive eruptions of various magnitudes (Matthews et al., 1997). The 18-20 April 1993 sub-plinian eruption produced an abundant pyroclastic flow (which extended up to $8.5 \mathrm{~km}$ away from the crater), an eruption column (up to $24 \mathrm{~km}$ in altitude) and constitutes the most important eruptive event in Central Andes within this last decade (Deruelle et al., 1996; Francis et al., 1993; Gardeweg \& Medina, 1994). This major event has been followed by several vulcanian eruptions (December 1993, July 1995, July 2000), minor explosions (for example October 2002, December 2003) and persistent degassing activity (e.g. Matthews et al., 1997; Viramonte \& Tassi, 2003). The volume of emitted magma during the April 1993 eruption has been estimated from geological observations to be $10^{8} \mathrm{~m}^{3}$ and between $10^{6}$ and $10^{7} \mathrm{~m}^{3}$ for the vulcanian eruptions (December 1993, July 1995 and July 2000) (Matthews et al., 1997). This recent activity resulted in significant morphological changes as revealed by aerial photographs acquired in 1981 and 1998 (Fig. 2). In particular

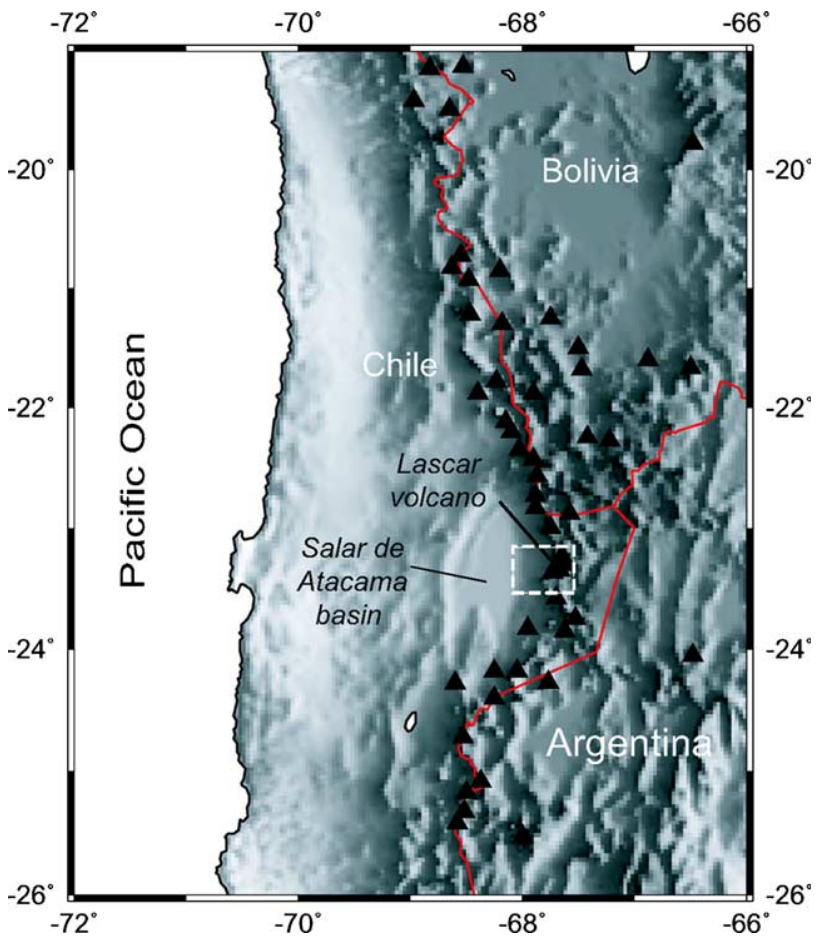

Fig. 1. Location map of the Salar de Atacama-Lascar area (north Chile). GTOPO30 DEM in greyscale. Black triangles show active volcanoes. White dotted rectangle indicates the studied area shown on Fig. 4.

a $\mathrm{N} 80^{\circ} \mathrm{E}$ fracture developed along the summit collapse craters. This fracture opening started in April 1993 (Matthews and Gardeweg, Personal Communication). One can expect that small-wavelength near-field topographic signals related to fracture opening or to central conduit dynamics could be detected there. Unfortunately no ground deformation network has ever been set up on Lascar volcano.

In this paper, we present the results of a detailed study based on satellite and field geodetic observations on Lascar volcano (Chile) carried out to investigate ground deformations (broad to near field signals) related to the recent activity (past 11 years). As discussed above, Lascar is one of the most active volcanoes in Central Andes, characterized by cyclic activity with dome growth and subsidence and has experienced several eruptions within the last decade which produced recognized topographic changes. Lascar is an excellent place to apply remote sensing techniques such as InSAR, because of the lack of any glacial cover, the scarcity of vegetation in the area and the dry stable atmospheric conditions during most of the year. In spite of the high elevation of Lascar (5592 m), these conditions allow us to conduct field geodetic surveys complementary to satellite observations.

We first present results based on a standard analysis and interpretation of ERS $(\mathrm{C}$ band $=5.6 \mathrm{~cm})$, JERS $(\mathrm{L}$ band $=23$ $\mathrm{cm}$ ) and ENVISAT (C band=5.6 cm) INSAR data. We complement these results with a quantitative estimation of tropospheric delays in our InSAR time-series data, using precipitable water vapour data from MODIS satellite measurements. We finally apply tropospheric corrections and use an accurate aerial photogrammetric DEM to re-process our InSAR 

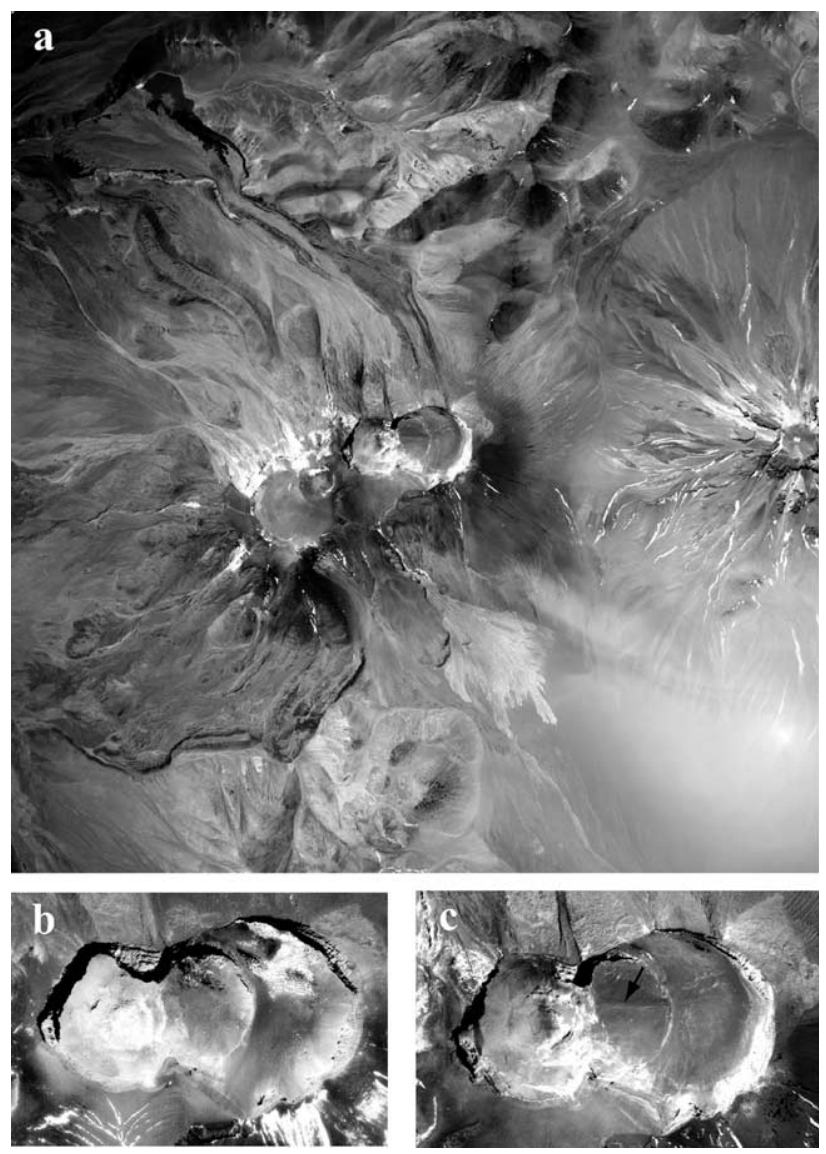

Fig. 2. Aerial photographs of the active area of Lascar volcano acquired in 1981 (b) and 1998 (a, c). (c) is a detail of (a) at the same scale of (b). Several significant morphological changes that occurred between both acquisition dates are visible here: (i) changes within the western crater containing the active conduit, (ii) the arcuate fractures located along the crater rims and (iii) an $\mathrm{E}-\mathrm{W}$ (N80E) fault crossing along the active craters (indicated by a black arrow).

data to investigate small wavelength deformations due to volcanic activity.

\section{INSAR data acquisition and processing}

Our dataset consists in 12 SAR images (descending orbits) acquired by the European Remote Sensing satellites (8 images ERS-1/2) and by Japanese Earth Resources Satellite (4 images JERS-1), respectively. This dataset enabled us to image the whole Lascar volcanic complex from July 1993 to October 2000 , covering the three recent vulcanian eruptions of December 1993, July 1995 and July 2000 (Fig. 3). Additionally, we began to complement our previous observations with a new time series on this volcano during 2003-2004 using newly available ASAR data provided by the European ENVISAT satellite.

The differential interferograms were computed by the two-pass method (Massonnet \& Feigl, 1998) using DIAPASON software (CNES, 1996) and precise orbit data produced by the Delft Institute for Earth-Oriented Space research (DEOS).

In a first approach, we interpolated using the kriging method a Digital Elevation Model (DEM) from 1:50000 digital maps provided by IGM (Instituto Geografico Militar, Chile) to remove the topographic contribution from the interferometry data. Later on, we took advantage of the recently available new global SRTM DEM that has advantageously replaced the topographic maps derived models to compute more accurate corrections, especially for INSAR applications. We linearly interpolated the original SRTM DEM (spatial resolution $90 \mathrm{~m}$ ) to a $45 \mathrm{~m}$ model in order to match with the INSAR resolution. Then we computed interferograms with a reduced content in high frequency topographic residuals.

\section{INSAR data analysis}

\subsection{General patterns of coherence and phase variations in Salar de Atacama-Lascar area}

The high signal-to-noise ratio of radar data in the Atacama region enabled the construction of coherent interferograms for the whole Lascar volcanic complex and its surrounding areas over time periods extending up to 4 years (Fig. 4). The interferograms are free of high frequency topography-related phase variations due to the quality of the SRTM DEM.

However, ERS interferograms (Fig. 4b, c) clearly show large wavelength phase gradients (roughly $\mathrm{E}-\mathrm{W}$ oriented) that correlate with the regional topography. Such phase gradients are likely to be produced by atmospheric variations (spatial and temporal variations in the water vapour, pressure or temperature parameters) in the lower part of the troposphere that affect the radar signal propagation between the image acquisition dates (Delacourt et al., 1998; Wadge et al., 2002; Zebker et al., 1997). In volcanic areas, they may produce artifactual fringes in interferograms (up to 2 or 3 fringes for $\mathrm{C}$ band) which may exhibit a similar wavelength and amplitude patterns to ground deformations (Beauducel et al., 2000; Massonnet \& Feigl,

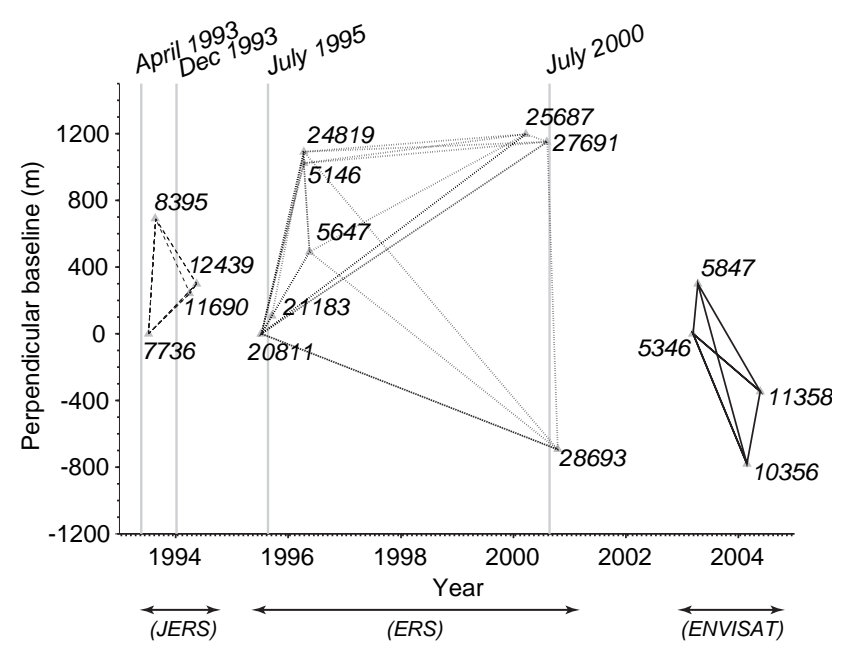

Fig. 3. ERS, JERS and ENVISAT SAR dataset available in this study are plotted in a perpendicular baseline (in $\mathrm{m}$ ) versus time. The bold number and solid or dashed lines denotes, respectively the orbits numbers and the corresponding interferograms. Light dashed areas indicate the main eruptive events occurred between 1993 and 2001. Note that baseline greater than $400 \mathrm{~m}$ are not suitable to make interferogram. 

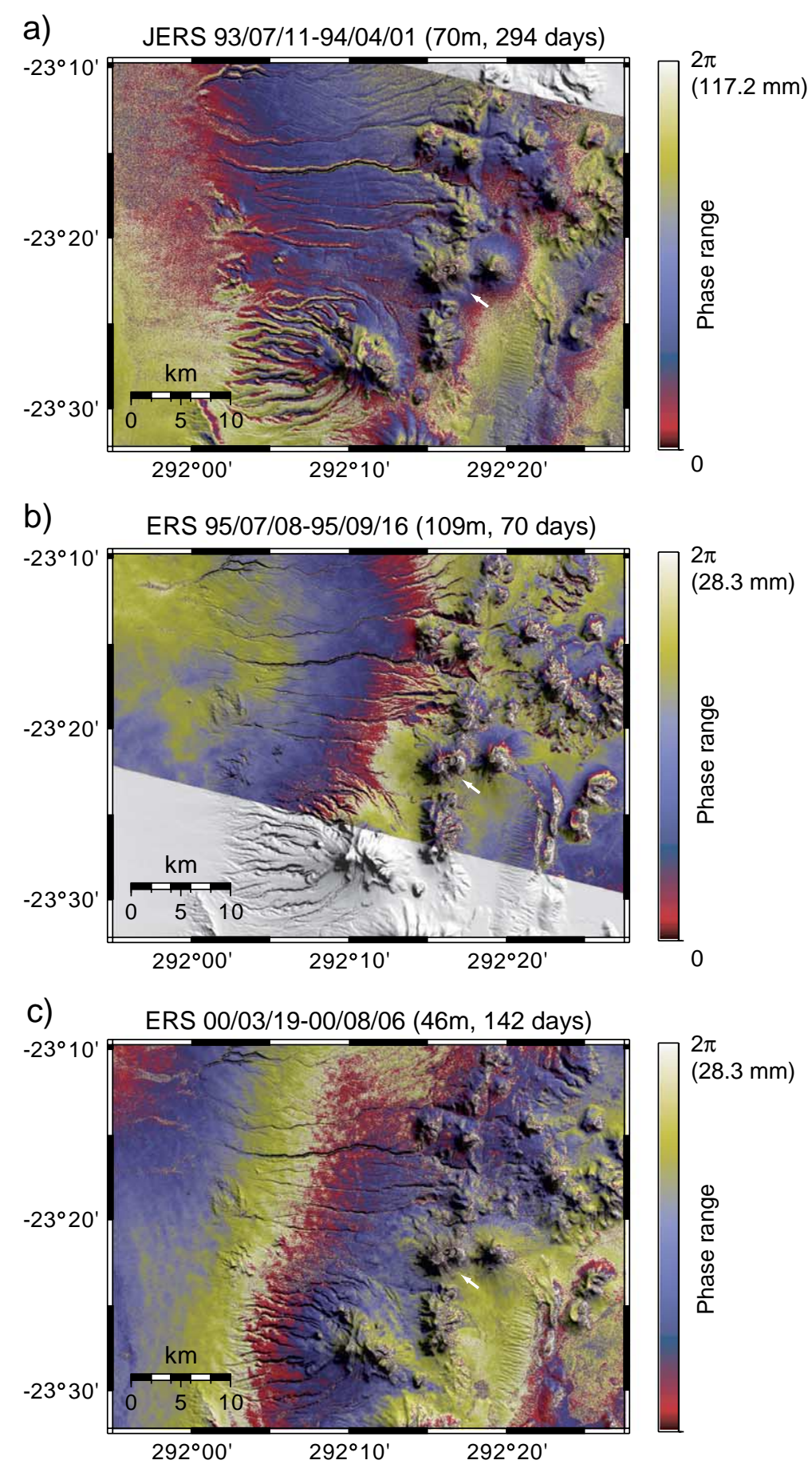

Fig. 4. Computed differential interferograms (ERS and JERS) over Salar de Atacama/Lascar area encompassing the most recent eruptive events of Lascar volcano: a) JERS interferogram orbits 7736-11690 (period 93/07/11-94/04/01, altitude of ambiguity 70 m, 294 days); b) ERS interferogram orbits 20811-21183 (period 95/ 07/08-95/09/16, 109 m, 70 days); c) ERS interferogram orbits 25687-27691 (period 00/03/19-00/08/06, 46 m, 142 days). The white arrow indicates Lascar volcano.

1998; Remy et al., 2003; Zebker et al., 2000). The study area is characterized by large altitude variations between Salar de Atacama $(2500-3000 \mathrm{~m})$ and Altiplano volcanic range (up to $6000 \mathrm{~m})$, and we thus suspect significant atmosphere water vapour variations in the area (Hanssen, 2001). In the following we quantify the impact of atmospheric variation on the interferograms.

\subsection{Evaluation of tropospheric contribution}

Due to the unpredictable character of atmospheric phase delays it has until recently been difficult to separate atmospheric delays from the effects of deformation and topography without external data on the atmospheric water vapour content such as measurements provided by radio-soundings or perma- 
nent GPS arrays. However, satellite estimates of the atmospheric water vapour content, performed by the National Aeronautics and Space Administration (NASA) using Moderate Resolution Imaging Spectro-radiometer (MODIS) instruments are now available at a global scale. Estimations of the total column of Precipitable Water Vapour (PWV), expressed in centimeters, can be retrieved at each satellite pass with a spatial resolution of $1 \mathrm{~km}$ and an accuracy of $5 \%$ to $10 \%$ (Gao \& Kaufman, 2003). These data are believed to provide a useful means to correct or interpret InSAR atmospheric effects ( $\mathrm{Li}$ et al., 2003; Moisseev \& Hanssen, 2003).

We first investigated the expected range of tropospheric phase delays in the study area. This task was achieved by analyzing a subset of MODIS Near Infrared Total Water Vapour Product (PWV product, MOD 05) images acquired for a two year period (2002-2004). Fig. 5 shows a graph of MODIS PWV measurements on the Salar de Atacama-Lascar area for this period. PWV values have been averaged for various altitude ranges corresponding to the Salar de Atacama depression $(2000-2600 \mathrm{~m})$, the base $(3800-4200 \mathrm{~m})$ and the summit (greater than $5000 \mathrm{~m}$ ) of main volcanic edifices (including Lascar volcano). The seasonal variations of PWV did not exceed $19 \mathrm{~mm}$ over Salar de Atacama depression and 6 $\mathrm{mm}$ on the summit of Lascar volcano over the two year period.

These time-series are in good agreement with past meteorogical studies of the which have shown large increases in atmospheric moisture at high altitude over the south American Altiplano occur during the summer months (December to March) (Garreaud, 2000). During the rest of the year PWV differences between most arid parts of the area and volcanic range decrease because of dry atmospheric conditions. At high elevation $(5000 \mathrm{~m})$ MODIS estimations of PWV are also in good agreement with those observed north of Lascar volcano at the Atacama Large Millimeter Array (ALMA) radio-telescope observatory $\left(23^{\circ} 01 \mathrm{~S}, 67^{\circ} 45 \mathrm{~W}\right)$ by NASA. The analysis of 41 years-long time series (from 1958 to 1998) of atmospheric soundings showed that PWV variations did not exceed $5 \mathrm{~mm}$ in the studied area over several decades (Erasmus, 2002). Based on these observations, we can infer that differential PWV may reach amplitudes up to $12 \mathrm{~mm}$ between Salar de Atacama depression and $5000 \mathrm{~m}$ (summit of most of volcanic edifices). Converted to slant phase delays (see Eq. (1) below), this amounts to 3 fringes in C-band interferograms for this altitude range, but only one fringe between the base and the summit of Lascar volcano. We can also deduce that the best period for InSAR applications in this volcanic region using ERS or Envisat C-band data is during drier period (March to December).

To examine the potential of the MODIS-PWV data for InSAR atmospheric correction on the Salar de AtacamaLascar Area, we selected an ASAR-ENVISAT interferogram containing similar fringe patterns to the ERS ones shown on Fig. 4. As MODIS and ENVISAT have a close crossing time in the studied area, we retrieve interferometric phase delays from the MODIS data using the approximations proposed by (Bevis et al., 1996; Hanssen, 2001; Li et al., 2003). Fig. 6a and b present the two MODIS images acquired at the same dates of the selected ENVISAT interferogram (February 22-May 2, 2004). The PWV differences corresponding to the ASAR interferogram are in the range of $8 \mathrm{~mm}$ in the studied area (see Fig. 6c). Due to clouds in the images, there are often missing values in MODIS PWV data. This prevents to compute pixelby-pixel zenith path delay to correct interferometry data. Nevertheless, the graph of PWV values versus elevation (Fig. $6 \mathrm{a}$ and b) computed using the whole cloud-free pixels for both acquisitions exhibits a typical exponentially water vapour decrease between the Salar de Atacama basin to the Andes Cordillera. This behaviour indicates that the atmosphere over the Salar de Atacama-Lascar area, is approximately horizontally homogenous, and the PWV varies most strongly with altitude. This makes it possible to model PWV variations using an empirical approach.

This task was performed using the following method. We modelled PWV variations using a piecewise polynomial form

Present-day MODIS measurements of PWV on Atacama / Lascar area

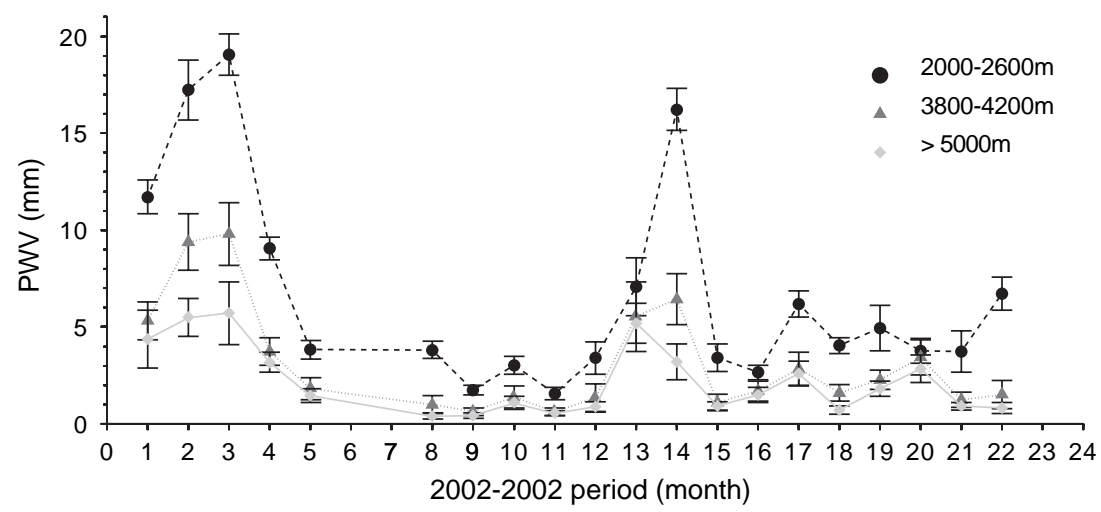

Fig. 5. Present-day satellite MODIS measurements of Precipitable Water Vapour (PWV) over Salar de Atacama-Lascar area. Measurements of PWV have been retrieved from MODIS satellite data and averaged for various altitude range corresponding to Salar de Atacama salar depression (2000-2600 m), basal (3800-4200 $\mathrm{m}$ ) and upper (greater than $5000 \mathrm{~m}$ ) parts of the volcanic range. Maximum variations of PWV between base and summit of Lascar volcano over a two years period (2002-2004) do not exceed $5 \mathrm{~mm}$, corresponding to a differential phase delay lower than one fringe in ERS interferograms and 0.35 fringe in JERS interferograms. 
a)
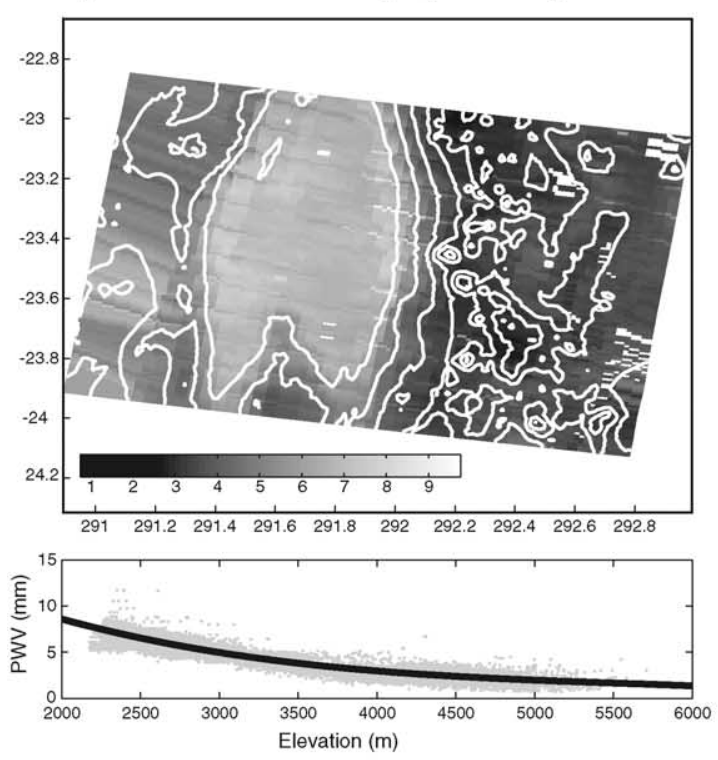

b)
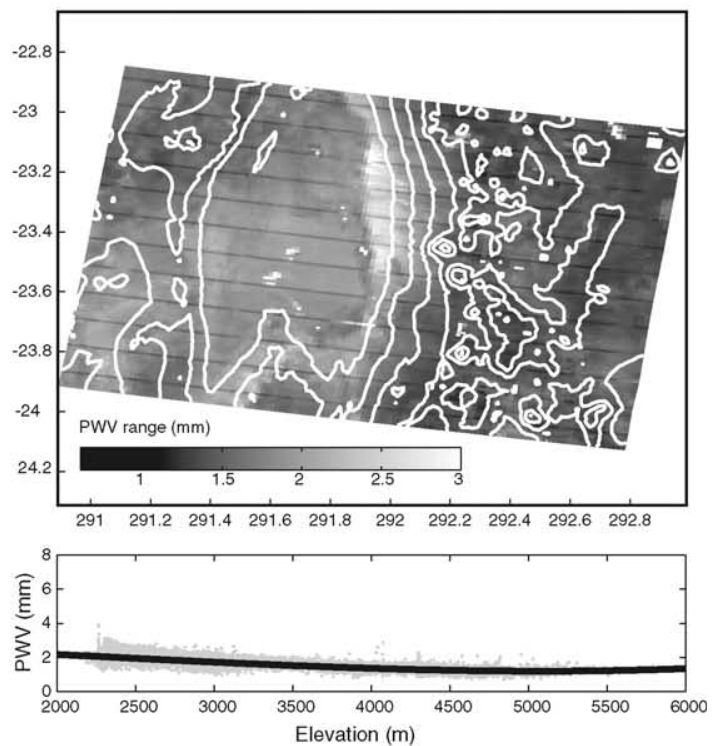

C) PWV difference (22/05/04-22/04/04)

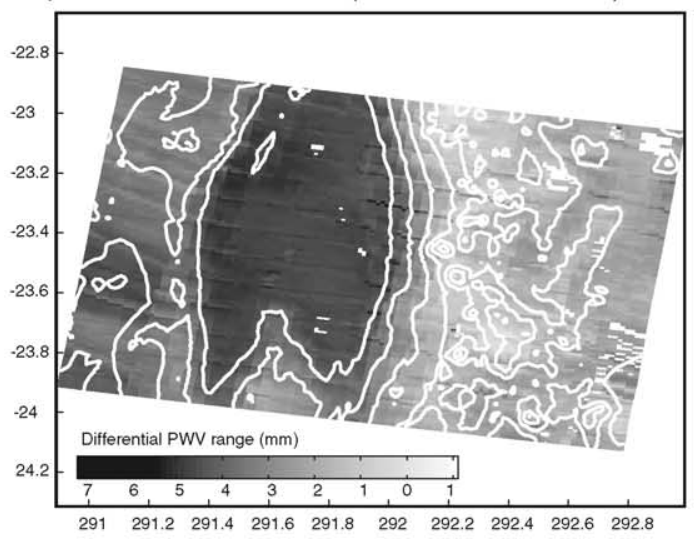

d)

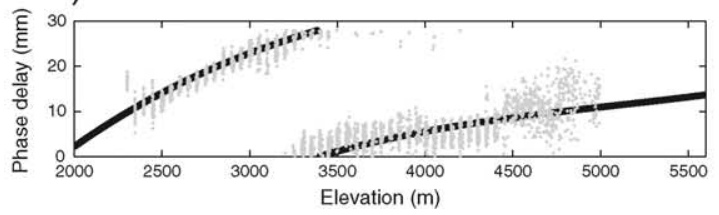

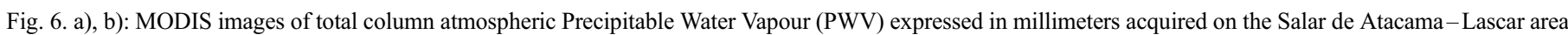

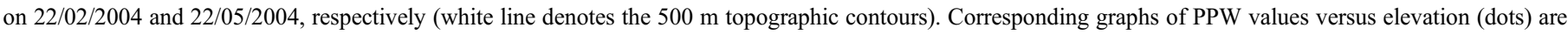

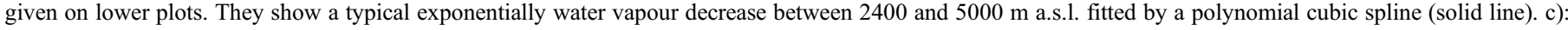

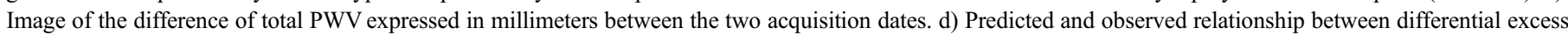

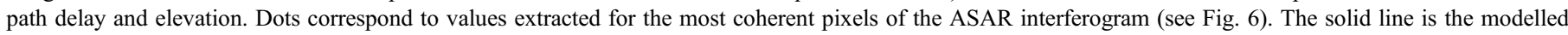
wrapped phase delay computed from MODIS data (see explanation in text).

of cubic-splines for each MODIS acquisition (22/02/04-02/05/ 2004). The spline function was constrained at 4 control altitudes $(2500,3000,4000$ and $5000 \mathrm{~m})$. The best model (solid lines in Fig. 6a and b) is the one which minimizes the discrepancies (in a least square sense) between the observed PWV values and those predicted. In order to compare with the differential slant path delay observed in the interferogram, we computed next the difference $(\triangle \mathrm{PWV})$ between the spline functions determined for each image. Next, we related the resulting difference to the predicted slant phase delay using the following equation proposed by Hanssen (2001):

$\phi_{p, q}=\frac{\Pi^{-1} \Delta \mathrm{PWV}^{*} 4 \pi}{\lambda \cos \theta_{\text {inc }}}(\mathrm{rad})$

where $\phi_{\mathrm{p}, \mathrm{q}}$ (radian) is the predicted interferometric phase difference between pixel $p$ and $q, \Pi$ is a typical constant factor $\approx 0.15$ (Bevis et al., 1996), $\Delta \mathrm{PWV}(\mathrm{mm})$ the resulting modelled difference computed above, $\lambda(\mathrm{mm})$ is the radar 
wavelength and $\cos \theta_{\text {inc }}$ is the cosine of the incidence angle. The predicted and observed relationships between phase delays and elevation data can be retrieved as seen in Fig. 6d where the dots represent the observed wrapped phase (expressed here in $\mathrm{mm}$ ), extracted for the most coherent pixels of the ASAR interferogram. The thick solid line represents the predicted wrapped phase delay computed as above. These estimates must be used with some caution given the uncertainties in the chosen value for $\Pi$ and the assumption of simple horizontally stratified atmosphere model. Nevertheless, the good agreement between the observed phase delays and those predicted using independent data, indicates that this approach is reasonable. The good agreement up to $4000 \mathrm{~m}$ in elevation (Fig. 6d) clearly demonstrates that the large phase signal observed is mainly due to tropospheric artefacts. At higher elevation, near the volcanic range, the correlation is less well defined because of a wider distribution of the observed phase. Observed and modelled phase delay differences are within $5 \mathrm{~mm}( \pm 0.3$ fringe). These are explained by lateral atmospheric heterogeneities, which are not taken into account in our approach.

The Fig. 7 displays the MODIS-based PWV corrections for the study area along an E-W transect from the Salar de Atacama basin to the volcanic arc (including the Lascar volcano). An E-W phase gradient (up to $25 \mathrm{~mm}$ phase delay) is clearly visible on lower to mid elevations of the raw ASARENVISAT interferogram (Fig. 7b) and is also seen on ERS ones (Fig. 4b, c). Once MODIS correction applied, the phase gradient signal is significantly reduced (Fig. 7c). These results show that PWV measurements as those obtained from MODIS or MERIS data provide a promising means to estimate the tropospheric contribution in such mountainous areas (Andean volcanoes for instance).

\subsection{Implications for ground deformation measurements}

The selected ERS and JERS interferograms presented on Fig. 4 encompass the three eruptions from December 1993, July 1995 and July 2000. In light of the previous results, the EastWest phase gradients observed on ERS interferograms (4b, 4c) clearly display a typical pattern (amplitude, wavelength, correlation with topography) associated with troposheric effects in Salar de Atacama-Lascar area. They cannot be linked with any regional ground deformation. It should be stressed that the convergence between Nazca and South American plates likely induces $\mathrm{E}-\mathrm{W}$ long term deformation of the fore-arc, but its order of magnitude and wavelength will produce negligible signals on the studied interferograms (Chlieh et al., 2004; Pritchard \& Simons, 2002). The JERS interferogram on Fig. 4a also exhibits a pattern of more than one fringe correlated with the topography in the Salar de Atacama-Lascar area. This strong correlation can be attributed to both the atmospheric signal and errors in the orbital state vector. Nevertheless, short wavelength topographic related fringes up to one fringe are observed between the base of the volcano edifices, located close to Lascar volcano, and their summits (around longitude $292^{\circ} 20^{\prime}$ on Fig. 4a). Such a value significantly exceeds that deduced from the time series analysis of MODIS data (max $\triangle \mathrm{PWV} 4$
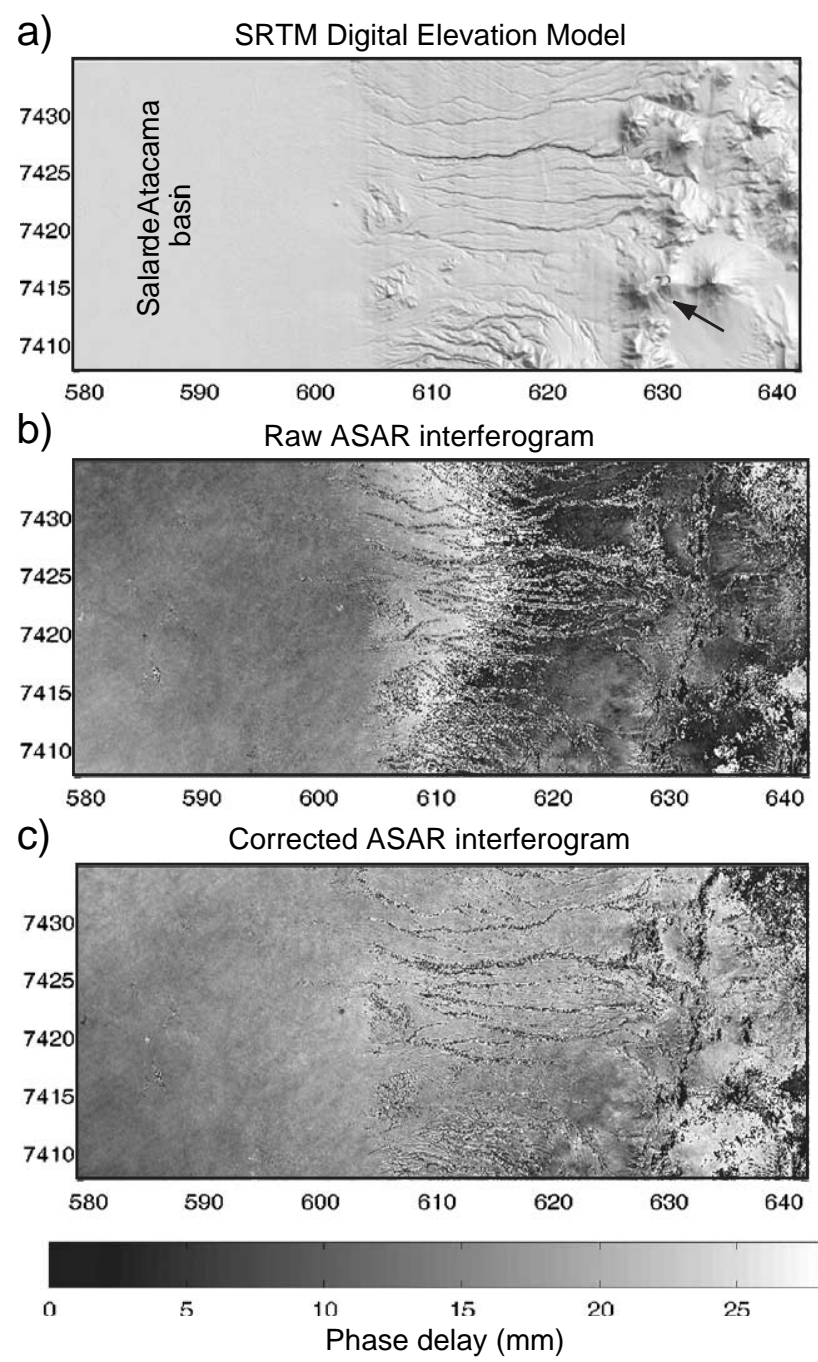

Fig. 7. Application of tropospheric correction on the Salar de Atacama-Lascar area. a) SRTM DEM (Lascar is indicated by a black arrow); b) Raw ASARENVISAT interferogram (orbit 10356-11358, 22/02/04-22/05/04) showing typical E-W phase gradients; c) same ASAR-ENVISAT interferogram corrected from tropospheric-induced phase delays using the wrapped phase delay modelling derived from simultaneous MODIS data (Fig. 5d).

$\mathrm{mm} \approx 0.30$ JERS fringe) and we conclude that these signals are mainly due to errors in orbital state vectors. Regarding possible ground deformation associated to volcanic activity around Lascar volcano, our InSAR time-series data lead to results similar to those obtained by Pritchard and Simons $(2002,2004)$. After correcting our interferograms for topographic and tropospheric contributions we find no large scale phase variations. We thus confirm the lack of broad scale volcanic deformation associated with recent explosive activity (from 1993 to 2000). Nevertheless, this observation should be moderated by the fact that in our ERS and JERS dataset no image was available to make interferogram on Lascar volcano spanning the April, 1993 eruption. We now focus on possible small scale deformation, particularly in the summit area. The SAR interferograms previously computed are not accurate enough for this purpose. This might be due to a possible loss of coherence in the active area or more probably to the limitation 
of the DEM used. In the following we investigate this point using a high resolution DEM centred on Lascar volcano.

\section{High resolution imaging of Lascar volcano}

\subsection{Photogrammetry/GPS DEM}

Most recent studies based on detailed observations on explosive volcanoes have shown that conduit-related dynamics might play a major role on their activity (e.g. (Melnick \& Sparks, 1999; Sparks, 1997; Voight et al., 1999). Investigation of possible small wavelength deformation related to crater and conduit dynamics requires accurate topographic corrections. We generated a photogrammetric DEM using digitized aerial stereo-photographs acquired in 1998 by Chilean Air Force services (SAF) for the 1:50.000 scale topography mapping. These data have been re-processed at the French Institut Géographique National (IGN France) using techniques well suited for mountainous areas (Top-Areo and Dauphin softwares developed at IGN France).

With the aim to constrain the DEM coordinates and altitude reference frames by ground control points, we carried out
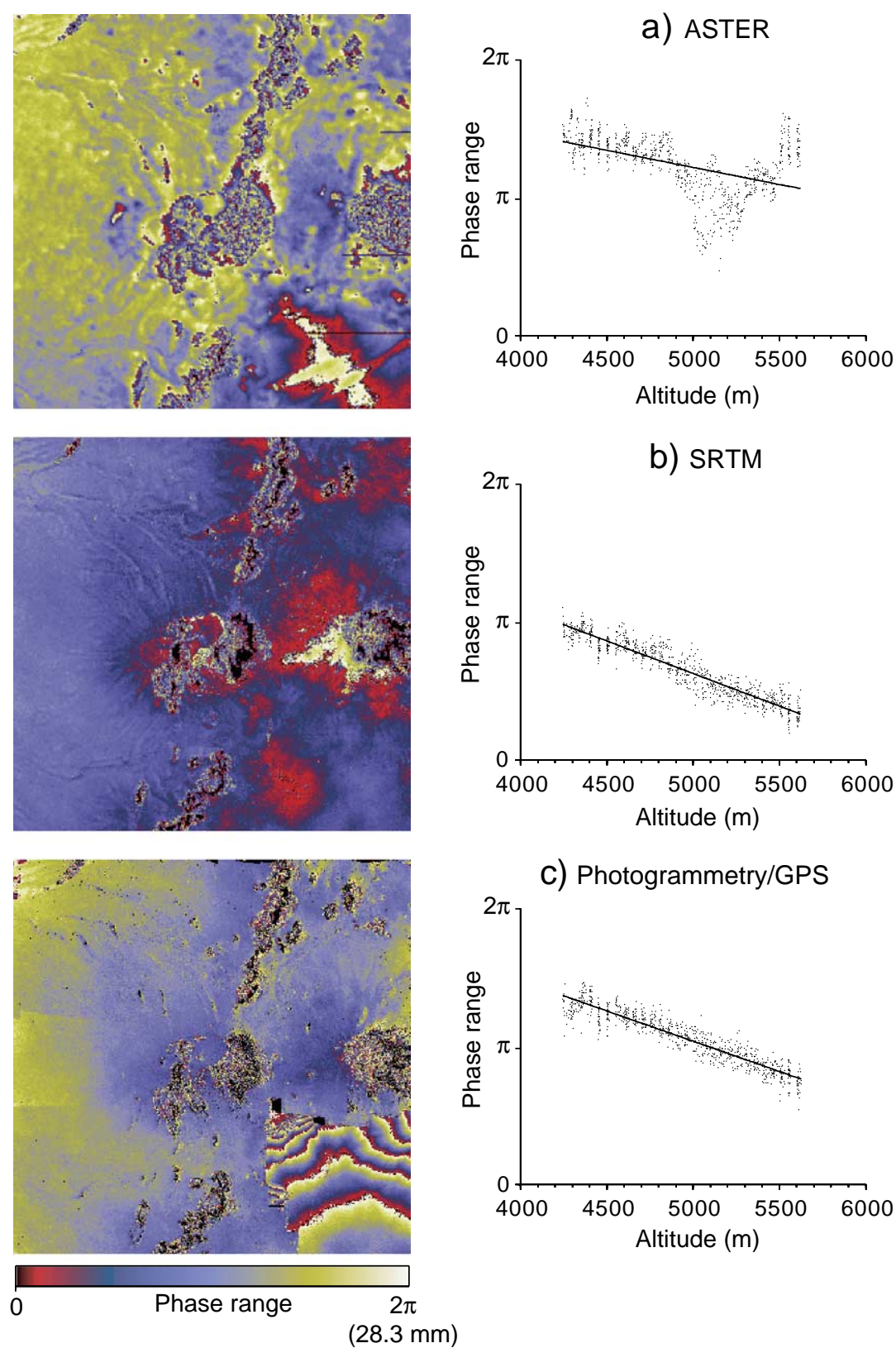

C) Photogrammetry/GPS

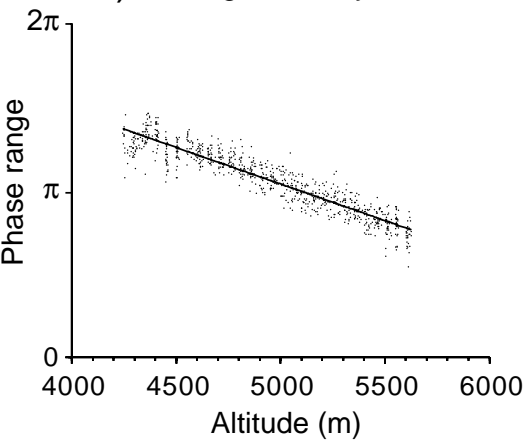

Fig. 8. Left) Tandem interferogram (13-14 April 1996, altitude of ambiguity $113 \mathrm{~m}$ ) of Lascar volcano computed with various Digital Elevation Models: a) ASTER (original resolution $30 \mathrm{~m}$ ), b) SRTM (original resolution $90 \mathrm{~m}$ ), c) Photogrammetry/GPS (original resolution $3 \mathrm{~m}$ ). Right) Corresponding phase-altitude relationships (dots) fitted with a linear trend (straight line). Both SRTM and photogrammetry/GPS DEM exhibit linear relationship with elevation enabling then a better correction of interferograms for tropospheric effects. Fringes in Fig. 8c result from incomplete topography correction as our photogrammetry DEM does not contain data on this south-east part of Lascar volcano (presence of a volcanic plume during aerial photo acquisition as seen on Fig. 2a). Note the excellent overall quality of the $30 \mathrm{~m}$ interpolated SRTM DEM validated here for Lascar volcano area using a $3 \mathrm{~m}$ resolution GPS DEM. 
several kinematic GPS surveys at Lascar volcano between 2002 and 2004. The GPS surveys were based on differential observations using dual-frequency Ashtech Z12 and Zxtreme receivers, from control sites referenced to IGS geodetic stations. The resulting accuracies in horizontal and vertical coordinates are estimated to be better than 5 and $10 \mathrm{~cm}$, respectively. The bundle adjustment was done using the software "Top-Aero" (IGN France) and was constrained by GPS coordinates collected during the early 2002 field survey. The resulting 3 $\mathrm{m}$ resolution DEM, produced by means of the correlation Dauphin software (IGN France), was then validated using all available kinematic GPS tracks carried out during 2002, 2003 and 2004 which provided thousands of ground control geodetic points (Fig. 10a). Based on this GPS validation, the vertical accuracy of this DEM is estimated to be better than \pm 7 and $5 \mathrm{~m}$ on volcano flanks and crater area, respectively.

We re-processed SAR images with this new DEM using a higher resolution (5 look in azimuth and 1 look in range) in order to reduce the noise while keeping a good ground resolution of about $20 \mathrm{~m}$. For this purpose, the digital photogrammetric DEM was resampled into a $20 \mathrm{~m}$ pixel spacing grid in order to match the SAR image resolution.

\subsection{Patterns of coherence and phase variations in Lascar crater area}

The improvement provided by this process for DinSAR imaging is clearly highlighted on Fig. 8 which compares the same one-day tandem interferogram computed with satellite derived (ASTER, STRM) and photogrammetry/GPS derived DEMs. The use of the photogrammetry/GPS DEM (8c) significantly increases both the overall and the summit area coherencies of the interferogram. It also reduces the number of topography related fringes that can be attributed to DEM inaccuracies. The relationships between phase and altitude for each interferogram are represented on Fig. 8. The linear behaviour observed on graph $8 \mathrm{c}$ makes it possible to correct more accurately the interferogram for residual topography related tropospheric effects than when using previous DEMs (Fig. 8a, b). This study also validates the excellent quality of the SRTM DEM, confirming that it is adequate for monitoring volcanic deformations at Lascar volcano over large to mid scales.

We then re-computed a coherence map of the Lascar volcano and surrounding areas with our new DEM, stacking all the available ERS interferograms having altitude of ambiguity greater than $45 \mathrm{~m}$ (Fig. 9). The spatial coherency is remarkably high western and northern flanks of Lascar, and remains acceptable in the summit active area (particularly on crater floors), even if a decrease in the coherence values is observed. We thus expect small scale deformations to be detectable in time-series interferograms.

\subsection{Implications for ground deformation measurements}

The precise topographic correction allowed us to observe a subtle phase variation in the summit area for the ERS

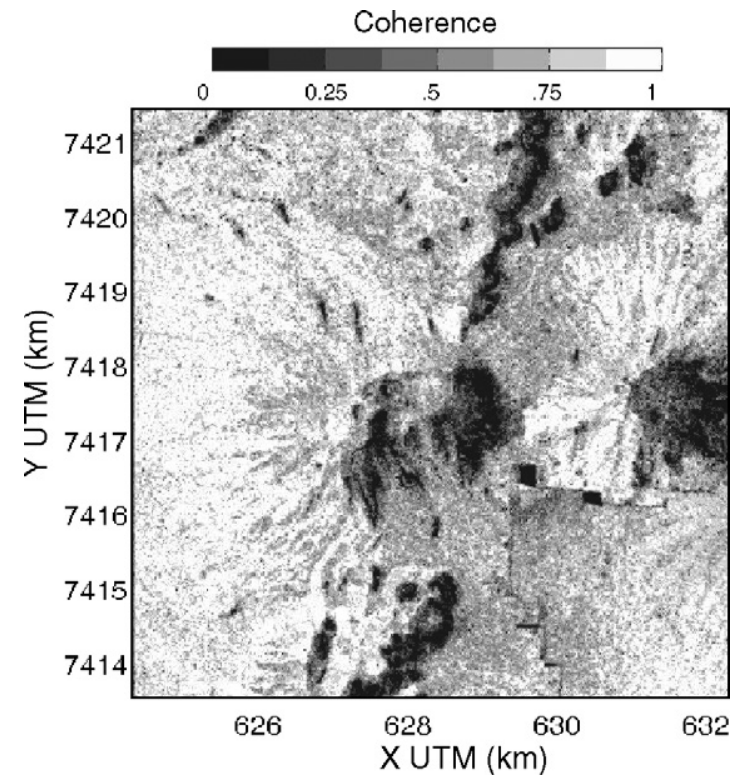

Fig. 9. Interferometric coherence map of Lascar volcano constructed from the stacking of individual coherence mask computed for each interferogram having an altitude of ambiguity greater than $45 \mathrm{~m}$. The grey colorbar indicates the normalized value of coherence from 0 (no coherence) to 1 (very high coherence). The white and light-gray pixels indicate where the coherence (value up to 0.7 ) is maintained for over several years and where ground deformation signals might be detected. Note the good observed coherence on the northern and western flanks and on the most parts of summit craters.

interferogram spanning from July 8th to September 16th, 1995 encompassing the July 20th eruption (Fig. 10). The nearly circular to elliptic signal extends has a dimension of about $500 \times 400 \mathrm{~m}$ in NS and EW directions, respectively, and reaches up to 0.6 fringe in amplitude. It also perfectly coincides both in size and location with one of the overlapping summit pit craters that have been the successive locus of most recent activity at Lascar volcano (Gardeweg \& Sparks, 1998).

The crater on which the signal is seen formed just east of the deepest and most active crater. It is also affected by the $\mathrm{N} 80^{\circ} \mathrm{E}$ active fissure with fumarolic activity, emplaced after the July 1993 paroxysmal eruption. This signal is not likely to be produced by DEM inaccuracies because it does not appear on the tandem interferogram used to check the overall accuracy of the new DEM (Fig. 8). Furthermore, it is detected in a coherent area. The signal is compatible with a phase variation produced by a lengthening of the distance to the ground of approximately up to $17 \mathrm{~mm}$ along the line of sight (LOS) of the satellite. We interpret this phase variation signal as a little subsidence of the crater floor detected during the two month inter-image period.

We did not detect any ground deformation signal for the other two recent vulcanian eruptions (December 1993, July 2000). Observations available for the July 2000 eruption did not provided coherent interferograms due to the snow cover that affected the higher parts of Lascar during 2000 southern winter. Therefore we cannot draw any conclusion about deformation for this eruption. For the December 1993 eruption, the available JERS data did not reveal any significant signal in the summit area. According to the 

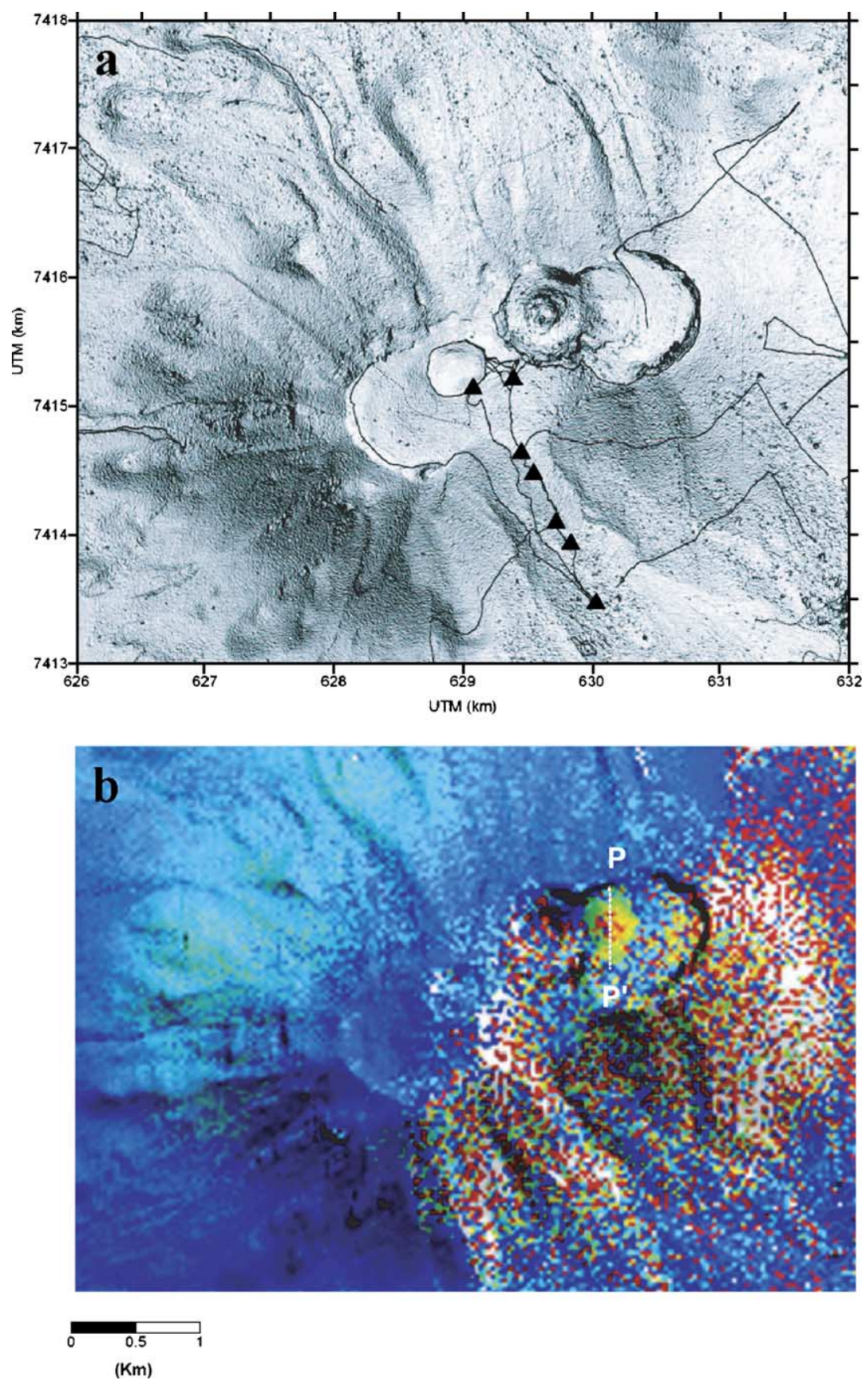

Fig. 10. a) High resolution photogrammetric/GPS DEM constructed from digitized aerial photographs (acquired in 1998 by SAF Chile) and ground GPS measurements. The dots represent the location of the kinematic GPS data acquired for this study during three field surveys (2002, 2003, 2004). Triangles denote GPS and microgravity benchmarks used as repetition sites during the 2002-2004 fieldworks. b) Observed interferogram orbits 20811-21813 (period 95/07/08-95/09/ 16, altitude of ambiguity: $85 \mathrm{~m}$ ) computed with the photogrammetric/GPS DEM and correction from tropospheric effects. The phase delays are indicated in millimeters. This new processing enables to detect a small scale ground subsidence signal (up to $17 \mathrm{~mm}$ ) located in the summit area within one of the collapse crater and centred on a major structural pattern (E-W fracture) parallel to the crater alignment (see Fig. 2).

standard resolution of these L-band data and to the accuracy level of JERS orbit determination, this result implies that no ground deformation above a $4 \mathrm{~cm}$ detection threshold (approximately one third of fringe) occurred during the observation period. It should also be stressed that the shortest time spanned by the interferograms is over nine months (11/ 07/93-01/04/94), which could be much larger than the time needed by the system to set on and return to its equilibrium state.

\section{Discussion}

The analysis of ERS and JERS data acquired between 1993 (posterior to April 1993) and 2000 clearly confirms that the recent eruptive activity at Lascar volcano did not produced detectable large wavelength ground deformation. This result also obtained by Pritchard and Simons $(2002,2004)$ from a comparable dataset favours the hypothesis that ground deformation associated with eruptive events on such explosive 
volcanoes is mostly confined in the summit active zones in relation with the subsurface conduit-related dynamics. The short wavelengths and the low amplitudes of these signals might explain that standard resolution of InSAR imaging is not accurate enough to detect such spatially limited topographic changes. As a matter of fact, ground based geodetic measurements in similar volcanic contexts have provided evidence that ground deformations is located in the vicinity of craters and domes during eruptive phase (Beauducel \& Cornet, 1999; Bonvalot et al., 2002; Mothes et al., 2000; Shepherd et al., 1998; Voight et al., 1999). This study provides the first interferometric measurement of such near-field ground deformation on an Andean volcano. This was achieved due to the use of an accurate topographic correction in our InSAR data processing.

The subsidence observed in this study has a sub-circular to elliptic shape that is very well confined within one of the Lascar's overlapping summit pit craters formed as a result of shallow plumbing system accommodation. Whereas the coherence of INSAR interferograms could easily decrease in the deeper crater hosting the present-day main active conduit, there is no evidence that this subsidence signal extends outside of the central crater (i.e. inside the close eastern or western craters). Based on this observation, we argue that the detected ground deformation reflects an episode of the crater floor subsidence that originates from a conduit-related process below the central crater. The present-day activity of this central crater is also attested by the recent reactivation of crater rims (collapse of the NE crater floor along arcuate subvertical fault scarps) and by the newly formed (post April 1993) $\mathrm{N} 80^{\circ} \mathrm{E}$ fracture (Fig. 2) that controls permanent degassing (Smithsonian Institution, 1995; Matthews et al., 1997). Our observations during recent fieldwork from 2002 to 2004 confirm that both crater rims and the $\mathrm{E}-\mathrm{W}$ trending fracture still have a role in the current degassing activity.

It is also clear that the crater subsidence evidenced here just one month after the July 1995 eruption is quite limited in time and amplitude. Therefore, the InSAR data available on Lascar volcano, do not allow us to constrain accurately the deformation timing nor to confirm that this subsidence reflects any long term or on-going process. Transient episodes of subsidence directly associated with eruptive events might be more probably invoked. Recent ground deformation and seismological observations, that we carried out at Lascar volcano during 2003-2004, could support this hypothesis. During this period, while no eruptive activity was reported, our observations confirmed the absence of surface or shallow processes related to the plumbing system dynamics. Our ENVISAT dataset acquired between March 2003 and May 2004 (Fig. 3) did not reveal any ground deformation in this crater area. Furthermore, a temporary seismological experiment (8 short period 3component stations recording continuously from June to September 2003) did not record any significant volcanic or volcano-tectonic event.

Summit pit craters observed on basaltic or andesitic volcanoes are generally thought to be produced by floor collapse into an underpressured reservoir caused by magmatic fluids withdrawal (Roche et al., 2001). Their formation and evolution are generally considered as resulting not only from one single event but from episodic collapses of variable magnitudes. According to the model of cyclic activity proposed by Matthews et al. (1997) for Lascar volcano, pressurization and depressurization occur in the magmatic conduit at shallow depth. Transient collapse processes accommodating subsurface changes in response to such cycles (e.g. Sparks, 1997, 2003) are then expected. Some of these changes have been observed by visual inspections during months preceding the July 1995 eruption. At that time, based on crater photographs, Smithsonian Institution (1995) concluded that "the active crater floor continued to subside, destabilizing the walls and inducing them to collapse".

A shallow deflating source involving a moderate volume or pressure change might thus be invoked here to explain the observed interferometric signal. In order to have a first order approximation of this involved volume, we carried out a simple modelling study assuming a volume change in an elastic media (Mogi, 1958). Solutions sought for depth and volume variations ranging from 100 to $1000 \mathrm{~m}$ (step $10 \mathrm{~m}$ ) and from 0 to $10^{4} \mathrm{~m}^{3}$ (step $10^{2} \mathrm{~m}^{3}$ ), respectively. The best fit model accounting for the observed signal ( $\mathrm{rms} 3 \mathrm{~mm}$ ) provides a source located at about $180 \mathrm{~m}$ depth below central crater floor with a volume variation of $2.10^{3} \mathrm{~m}^{3}$ (Fig. 11). This result is compatible with those estimated from scaled analogue modelling of subsurface structures and collapse mechanisms of calderas (Marti et al., 1994) and summit pit craters (Roche et al., 2001).

Possible candidates for underpressure of a magmatic conduit or reservoir are flank eruption, magma degassing, re-intrusion elsewhere or volume reduction by hydrothermal dissolution and alteration (Lopez \& Williams, 1993). Subsurface magma degassing, dissolution or alteration processes might be consis-

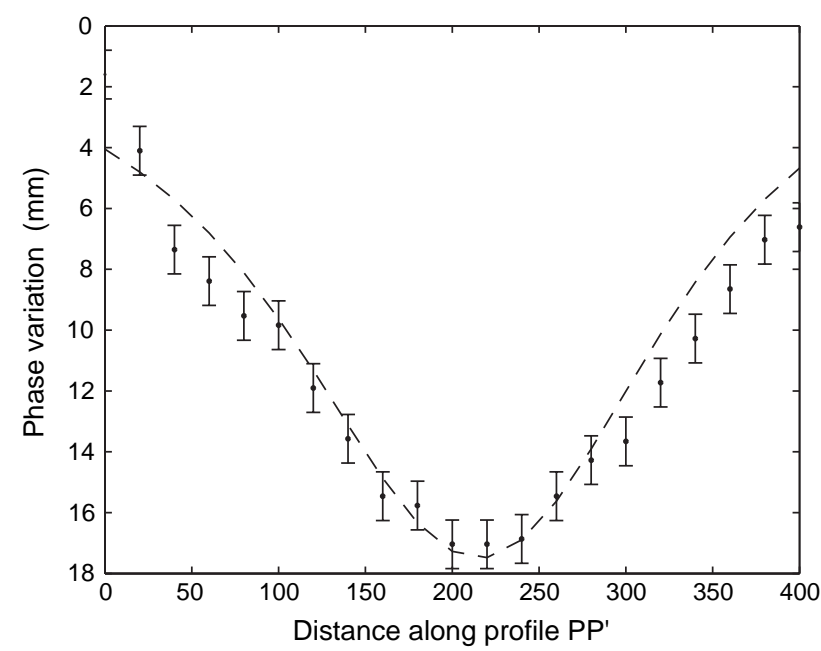

Fig. 11. Observed and computed ground displacement along a NS profile $\mathrm{PP}^{\prime}$ (see location in Fig. 10) crossing the central crater. Dots are the observed ground displacement (in $\mathrm{mm}$ ) extracted for coherent each pixel of Fig. 9b, dashed line is the theoretical computed effect for the best fit model (see text). Error bars indicate the estimated standard deviation of the observed displacement. 
tent with the visual observations carried out at Lascar within this period and with the model proposed for cyclic activity at Lascar (Matthews et al., 1997). Removal of magmatic fluids (upraised magma or gas) subsequent to the July 1995 eruption, that mostly took place from the deeper crater (just west of this deforming central crater), could have produced a pressure release at subsurface levels and triggered a moderate crater floor collapse. A reactivation (possible incremental opening) of the post 1993-eruption $\mathrm{E}-\mathrm{W}$ fracture crossing the central crater can be also considered. However, it should be stressed that the lack of geochemical or geophysical data does not allow us to better constrain the inferred process. Given the limitations of the current observations, we believe that more sophisticated modelling or interpretation would be too speculative.

Additional observations will be necessary to determine which factors control the ground deformation processes associated with crater collapses at Lascar and how they propagate in the volcano subsurface (transient or chaotic piston-like, continuous elastic deformation, etc.). Nevertheless, this first study confirms that satellite SAR interferometry data, using well adapted data processing (high resolution DEM and tropospheric corrections for instance) can be successfully used at Lascar volcano to measure small scale conduit-related ground deformations as described in such context by Sparks (1997), Melnick and Sparks (1999). The understanding and prediction of the current activity now requires further observations to monitor new episodes of subsidence of the central crater floor, possible fault reactivations of the $\mathrm{E}-\mathrm{W}$ trending fracture or reactivations of the annular circum-crater fractures.

\section{Conclusions}

The analysis of INSAR (ERS, JERS, ENVISAT) and other complementary satellite, aerial and ground data acquired on Lascar volcano provided new results both: (i) for the characterization and understanding of the Lascar present-day activity and (ii) in terms of general application and potential of satellite InSAR imaging for the understanding of ground deformation style and behaviour of Andean volcanoes.

The main results we obtained for Lascar volcano are as follows:

(i) A systematic analysis of the available radar interferometry data allowed us to monitor surface changes with a few centimeters accuracy associated with Lascar cyclic activity within the 1993-2000 period. In spite of limited data availability, our study confirms that no persistent large scale ground deformations could be detected for the sequence of vulcanian eruptions after the April 1993 subplinian eruption.

(ii) The use of a high resolution DEM resulting from the combination of aerial photogrammetry data and ground GPS measurements significantly improved the accuracy of InSAR imaging on the whole Lascar volcanic structure. This process allowed us to detect sub-centimeter ground displacements in the active area and to localize the present-day locus of active deformation. Post-eruptive crater subsidence associated with probable degassing at subsurface levels beneath the central crater has been evidenced and quantified for the first time. This result is consistent with the conceptual dynamic model proposed by Matthews et al. (1997) in which magmatic conduit dynamics plays a major role in overpressure generation for Lascar cyclic eruptive activity. It might also contribute to better design the future monitoring tasks of this edifice.

(iii) We provided a quantification of tropospheric effects in the Lascar-Salar de Atacama area. Significant spatial and temporal variations of the water vapour content in the atmosphere (PWV), estimated from spectrometer satellite data (MODIS), are identified as the main source of artifactual fringes appearing at various scales on the interferograms. We suggest limiting InSAR data acquisition to the drier season (March to December) if the main goal is to detect small-scale ground-deformations in this area. Satellite spectrometer and radar (ASARENVISAT) data are now available simultaneously, and systematic corrections can be easily applied to significantly improve the large-scale ground deformation maps derived from InSAR data.

In light of the results of this study and those provided from other recent InSAR studies conducted in Andes (Pritchard and Simons, 2004), it appears that the current volcanic activity of Andean volcanoes is likely to produce large and small scale ground deformations that can be successfully detected from space. As they are controlled by deep or near surface magmatic activity, they are therefore a good indicator of activity state and of the size and location of deep or subsurface magmatic bodies. Consequently, a precise monitoring of both far-field and near-field surface displacements should eventually contribute to a better understanding of such explosive volcanoes dynamics.

New simultaneous satellite radar (ENVISAT) and spectrometer (MODIS, MERIS) data availability increases the potentialities to offer more systematic high resolution imaging of deformation fields at various scales. We believe that the methodologies, applied in this article to one of the most active volcanoes of Central Andes, might be extended to other volcanic active centres. They are expected to complement active deformation monitoring in remote or dangerous volcanic areas, and are likely to be particularly important in areas that are not continuously monitored by geodetic networks. This methodology should then contribute to guide future monitoring strategies and therefore to better understand the volcano dynamics and improve the eruption forecasting.

Finally, according to its intense cyclic activity and with the exceptional surface and atmospheric applications for InSAR imaging in Central Andes, the Lascar volcano may be considered as an excellent natural laboratory, among the Andean volcanic arc, for the study of active explosive volcanoes and development of satellite based monitoring techniques. 


\section{Acknowledgments}

We thank our colleagues F. Adragna, F. Amelung, P. Briole, N. Pourthié, M. Pritchard for constructive exchanges on SAR interferometry data acquisition and processing. We thank F. Amelung who kindly provided us 3 ERS images used in this study. We are also grateful to O. Jamet who initiated the realisation of the photogrammetric DEM in collaboration with IGN-MATIS. We benefited from helpful discussions with S. Matthews, M. Gardeweg and E. Calder on the dynamics of Lascar volcano. We are grateful to the three anonymous reviewers whose comments helped us to improve significantly our manuscript. Discussions and corrections of the English by M. Falvey were much appreciated. The ERS and ENVISAT data have been acquired through ESA research projects ( $n^{\circ} 857$, Category 1 project $n^{\circ} 2899$ ). This study has been supported by IRD (Dept. DME, DSF) by INSU (Programme PNRN, GRD INSAR), UMR5563 (LMTG) and IPGP (contribution 2103). Support to the field survey logistic has been provided by IRD (Representation in Chile), IPGP and University of Chile (Department of Geophysics) and FONDECYT-CONICYT project $\mathrm{n}^{\circ}$ 1030800. A. Pavez benefited from a PhD thesis grant from IRD (Dept. DSF) and of a sponsorship from GARS (IUGSUNESCO) programme.

\section{References}

Beauducel, F., \& Cornet, F. H. (1999). Collection and three-dimensional modeling of GPS and tilt data at Merapi volcano, Java. Journal of Geophysical Research, 104, 725-736.

Beauducel, F., Briole, P., \& Froger, J. L. (2000). Volcano wide fringes in ERS synthetic aperture radar interferograms of Etna (1992-1999): Deformation or tropospheric effect? Journal of Geophysical Research, 105(B7), 16391-16402.

Bevis, M., Chiswell, S., Businger, S., Herring, T. A., \& Bock, Y. (1996). Estimating wet delay using numerical weather analysis and predictions. Radio Sciences, 31(3), 447-487.

Bonvalot, S., Gabalda, G., Remy, D., Pavez, A., Diament, M., \& Mothes, P. (2002). Assessment of ground deformation measurements on Andean volcanoes using SAR interferometry and GPS data. Proceedings of $5^{\circ}$ ISAG, Toulouse, France (pp. 97-100).

Chlieh, M., De Chabalier, J. B., Ruegg, J. C., Armijo, R., Dmowska, R., Campos, J., et al. (2004). Crustal deformation and fault slip during the seismic cycle in the North Chile subduction zone from GPS and InSAR observations. Geophysical Journal International, 158, 695-711.

CNES (1996). Philosophie et mode d'emploi de la chaîne logicielle interférométrique. Toulouse, France: DIAPASON.

Delacourt, C., Briole, P., \& Achache, J. (1998). Tropospheric corrections of SAR interferograms with strong topography. application to Etna. Geophysical Research Letters, 25, 2849-2852.

Deruelle, B., Figueroa, O., Medina, E., Viramonte, J., \& Maragno, M. (1996). Petrology of pumice of April 1993 eruption of Lascar (Atacama, Chile) Terra Nova, 8, 191-199.

Dvorak, J. J., \& Dzurisin, D. (1997). Volcano geodesy: The search for magma reservoirs and the formation of eruptive vents. Review of Geophysics, 35, $343-384$

Dzurisin, D. (2003). A comprehensive approach to monitoring volcano deformation as a window on the eruption cycle. Review of Geophysics, 41.

Erasmus, D. A., (2002). An analysis of cloud cover and water vapor for the ALMA project: A comparison between Chajnantor (Chile), Chalviri (Bolivia) and five sites in Argentina using satellite data and a verification of satellite PWV measurement. The ALMA Project, European Southern Observatory, Final Report. 66814/ODG/02/6419/GWI/LET (Available from: http://www.eso.org/genfac/pubs/astclim/espas/radioseeing).

Francis, P. W., Self, C. M., Oppenheimer, C., \& Rothery, D. A. (1993). The April 1993 eruption of Lascar North Chile, observations and inference (abstract). Transactions, $A G U, 74,651$.

Gao, B. -C., \& Kaufman, Y. J. (2003). Water vapor retrieval using Moderate Resolution Imaging Spectroradiometer (MODIS) near-infrared channels. Journal of Geophysical Research D, 13. doi:10.1029/2002JD003023.

Gardeweg, M. C., \& Medina, E. (1994). La erupción subpliniana del 19-20 de Abril de 1993 del volcan Lascar, $N$ de Chile, $7^{\circ}$ (pp. 299-304). Santiago: Congreso Geologico Chileno.

Gardeweg, M., Sparks, R. S. J., \& Matthews, S. J. (1998). Evolution of Lascar volcano. Journal of Geological Society of London, 155, 89-104.

Garreaud, R. D. (2000). Intraseasonal variability of moisture and rainfall over South American Altiplano. Monthly Weather Review, 128, 3337-3346.

Hanssen, R. (2001). Radar interferometry data interpretation and data analysis. Remote sensing and digital image processing. Dordrecht, $308 \mathrm{pp}$.

Li, Z., Muller, J. P., \& Cross, P. (2003). Comparison of precipitable water vapor derived from radiosonde, GPS and Moderate-Resolution Imaging Spectroradiometer measurement. Journal of Geophysical Research, 108. doi: $10.1029 / 2003 \mathrm{JF}=\mathrm{D} 003372$.

Lopez, D. L., \& Williams, S. N. (1993). Catastrophic volcano collapse: Relation to hydrothermal alteration. Science, 260, 1794-1796.

Marti, J., Ablay, G. J., Redshaw, L. T., \& Sparks, R. S. J. (1994). Experimental studies on collapse calderas. Journal of Geological Society of London, 151(6), 919-929.

Massonnet, D., \& Feigl, K. L. (1998). Radar interferometry and its application to changes in the Earth's surface. Reviews of Geophysics, 36, $441-500$.

Matthews, S., Gardeweg, M. C., \& Sparks, R. S. J. (1997). The 1984 to 1996 cyclic activity of Lascar volcano, Northern Chile: Cycle of dome growth, dome subsidence, degassing and explosive eruptions. Bulletin Volcanologique, $59,72-82$.

Melnick, O., \& Sparks, R. S. J. (1999). Non-linear dynamics of lava dome extrusion. Nature, 402, 37-41.

Mogi, K. (1958). Relations between the eruptions of various volcanoes and the deformation of the ground surface around them. Bulletin Earthquake Research Institute of Tokyo, 36, 99-134.

Moisseev, D., \& Hanssen, R. (2003). Towards an atmosphere free interferogram; first comparison between ENVISAT's ASAR and MERIS water vapor observations. International Geoscience and Remote Sensing Symposium Toulouse, France, 21-25 July 2003, cdrom, 4 pp.

Mothes, P., Garcia, A., Aguilar, J., Viracucha, D., Caceras, V., Jaramillo, R., et al. (2000). Inflationary/deflationary cycles related to repetitive dome growth and destruction as seen in tiltmeter and GPS data: Guagua Pichincha volcano, Ecuador. Eos, Transactions, AGU, 81(48).

Pritchard, M. E., \& Simons, M. (2002). A satellite geodetic survey of large scale deformation of volcanic centres in the central Andes. Nature, 418, $167-170$.

Pritchard, M. E., \& Simons, M. (2004). An InSAR-based survey of volcanic deformation in the central Andes. G3, 5(2), Q02002. doi:10.1029/ 2003GC000610.

Remy, D., Bonvalot, S., Briole, P., \& Murakami, M. (2003). Accurate measurement of tropospheric effects in volcanic area from SAR interferometry data: Application to Sakurajima volcano (Japan). Earth and Planetery Science Letters, 213(3-4), 299-310.

Roche, O., van Wyck de Vries, B., \& Druit, T. H. (2001). Sub-surface structures and collapse mechanisms of summit pit craters. Journal of Volcanology and Geothermal Research, 105, 1-18.

Shepherd, J. B., Herd, R. A., Jackson, P., \& Watts, R. (1998). Ground deformation measurements at the Soufriere Hills volcano, Montserrat: Rapid static GPS measurement June 1996-June 1997. Geophysical Research Letters, 25, 3413-3416.

Smithsonian Institution. (1995). Lascar, Bull. Global Volcanism Network, 20(3).

Sparks, R. S. J. (1997). Cause and consequence of pressurisation in lava dome eruption. Earth and Planetary Science Letters, 150, 177-189. 
Sparks, R. S. J. (2003). Forecasting volcanic eruptions. Earth and Planetary Science Letters, 210, 1-15.

Viramonte, J., \& Tassi, F. (2003). Global Volcanism Network Bulletin available at http://www.volcano.si.edu

Voight, B., Sparks, R. S. J., Miller, A. D., Stewart, R. C., Hoblitt, R. P., Clarke, A., et al. (1999). Magma flow instability and cyclic activity at Soufriere Hills volcano, Montserrat, British West Indies. Science, 283, 1138-1142.

Wadge, P., Webley, W., James, I. N., Bingley, R., Dodson, A., Waugh, S., et al. (2002). Atmospheric models, GPS and InSAR measurements of the tropospheric water vapour field over Mount Etna. Geophysical Research, 29.

Zebker, H. A., Rosen, P. A., \& Heinsley, S. (1997). Atmospheric effects in interferometric synthetic aperture radar surface deformation and topographic maps. Journal of Geophysical Research, 102, 7547-7563.

Zebker, H. A., Amelung, F., \& Jonsson, S. (2000). Remote sensing of volcano surface and internal processes using radar interferometry. Washington, DC: American Geophysical Union, 179-205 pp. 